\title{
Exploration and Practice of Graduate Classification Training System
}

\author{
Tingting Wang \\ School of Electrical Engineering \& Information, \\ Northeast Petroleum University, \\ Daqing, China \\ Shibin Li \\ College of Petroleum Engineering, \\ Northeast Petroleum University, \\ Daqing, China
}

\author{
Wanchun Zhao* \\ College of Petroleum Engineering, \\ Northeast Petroleum University, \\ Daqing, China \\ *Corresponding author
}

\author{
Fengcai Huo \\ School of Electrical Engineering \& Information, \\ Northeast Petroleum University, \\ Daqing, China
}

\begin{abstract}
This paper presents a detailed analysis of some defects and deficiencies exposed to the current our country University Graduate Cultivation Mechanism and the graduate program. In combination with the latest domestic and international postgraduate training system and the practical characteristics of graduate students "learning", "art" system, classification culture mode, improve the shortcomings of previous training system.
\end{abstract}

Keywords- graduate education; training mechanism; teaching system; classification culture

\section{INTRODUCTION}

The postgraduate classification of training pattern in more developed countries has a hundred years practical application, and it is regarded as an effective means of fostering industrial development that plays an important role on promoting the economic development. Our country is late for the application of the implementation of classification training and education mode, Though there has been certain achievements, it is always in the up and down and it isn't spreading well. Analyzing its causes: firstly, the theory of learning seriously out of line with the actual production, and closed education separates from social progress. Secondly, under the restrictions of current system, our country planned economy system in the long term, the cultivation of advanced talents is limited to narrow professional education of school, and the cultivation of practice ability is restricted on relatively single practice for school; thirdly too much emphasizing on the academic cultivation of graduate students ignores the practice of actual production engineering and puts talent cultivation of "industry-university-institute" cooperation mainstream out of the development of high education[1]. Therefore, our institute of oil and gas well engineering developed a graduate student "learn", "art" points system after years of teaching reform and practice, and established the classified training mode of teaching system.

\section{BRIEF INTRODUCTION OF POSTGRADUATE TRAINING MODE}

Long term since our college graduate education system and training mode are carried out in a closed state ${ }^{[2]}$, under the existing petroleum engineering graduate education system, spending most of the energy on studying and researching the theory of knowledge leads to that most of the oil graduates can not adapt to the demand of oil field and research and development of oil companies. They also can not solve the practical problems and the theory knowledge can not combine with the actual problems well. The research institute which study's of the theoretical knowledge needs less quantity of talents, and the applied talents oil enterprise required are lacking. So the students who are trained by the current graduate education are lack of training practice and innovation ability and it is not fit well with the demand of social economic development ${ }^{[3]}$.

With the number of graduate students in various colleges and universities expending continually in recent years, graduate academic culture mainly relies on school internal re-sources and outside resources supply in short, which causes the tight of teacher resources, equipment and scientific research funds, seriously affecting the quality of post-graduate students of oil and gas wells. Although it has eased after the reformation and restriction in recent years, there still exists a lot of serious problems. On the other hand, the traditional closed education system cannot meet the cultivation of innovative talents of the moment, it leads that the talents cannot effectively combined with the actual production. For the basic production knowledge is mastered insufficiently, causing oil enterprises lack of a large number of practical application in oil enterprises.

\section{THE ESTABLISHMENT OF " SCIENCE ", " ART" DIVIDE AND CONQUER, CLASSIFIED TRAINING MODE}

\section{A. Professional Degree Postgraduate Student Enrollment}

Professional degree is relative to academic degree, and the goal of training is different from academic degree. Oil and gas engineering professional degree education aims to cultivate 
high level of technical and management personals who can solve the problems of oil field. The occupation direction of the academic degree of oil and gas wells engineering postgraduate training is scientific research and the main target is to update the petroleum scientific and technical development. In order to meet the urgent demand of high level professional talents in today's petroleum engineering construction and social development, Our institute is promoting the development of education of professional degree postgraduate, and conducted a large-scale expansion. With the increase of the development of professional degree postgraduate, the past single cultivating mode of academic graduate students is difficult to adapt to the new situation of oil field talent demands.

\section{B. Setting Diversified Classification Training Mode}

With the diversified targets training to the postgraduate, we also should pay attention to the diversified manner of cultivation plan. For oil and gas well engineering academic graduate training, they strengthen on the theory basis, at the same time, we should focus on cultivating the innovation ability of academic and the change of the way of thinking. While for the professional master postgraduate students, they are required not only to master steady professional foundation knowledge, but also to have strong ability of scientific research and the development of technology, they can combine the theory knowledge with the actual production well when they graduate, and can make good use of the latest research results on the technical invention and innovation of oil and gas well. Therefore, the academic talents focus on the optimized cultivation process. For applied talents, they should promptly unite today's oil industry technical requirements, can reflect the characteristics of combination of applicability and flexibility in curriculum design and the ways of training, and actively output the excellent talents in petroleum industry and explore the training mode of cooperation with the oil unit personnel.

\section{Establish Postgraduate Course System in the Classification Development}

Strengthen the collaboration between the oil and gas well engineering and each oil unit and research and development center. According to the new needs of site technology in the oil and gas well, a set of postgraduate course system with practice and academic frontiers is developed, which constantly improving the graduate students practical ability to solve technical problems and scientific inventions. According to the major direction and the interest direction combined with their own actual situation, each student can take a percentage of the professional courses under the guidance of instructors. In terms of cultivating postgraduate course construction in the classification, a full-time postgraduate course system should be referred, and the advantage of its focus on professional basis should be absorbed, and the subject type and quantity of elective course should be increased, and the development of his personality and interests should be placed emphasize on cultivating, in order to stimulate students' creative ability in the greatest degree. Flexible cultivating system of postgraduate course can be more perfect in the way of postgraduate cultivation in oil and gas well engineering, and broaden the students' knowledge, which has a solid foundation for further classification training, and improves the overall comprehensive ability and quality of the postgraduate.

\section{Establish Different Cultivating Goals}

For academic master's graduate students, because the number of students is great and the resources of the school are limited, under the target of classification cultivating, it is necessary that professional instructors of the campus spend more energy to cultivating academic creation ability of the postgraduates, and through the leadership and guidance to cultivate its scientific research and development ability of the second instructor outside the school; for a small number of applied master's graduate students, under the target of classification cultivating, it is necessary that cooperating with oil companies and scientific research units can be adopted, and transferring applied master's graduate students to the various enterprises and scientific research units, and combining professional knowledge and practical work effectively as soon as possible, and going into the actual production as soon as possible. Because the cultivation of applied master's graduate students that is only replied on campus academic instructors is not enough, it is necessary that campus academic instructors develop the students with senior engineering technical personnel in the oilfield, and achieve a good combination of theory with practice. The professional master graduate students in this kind of cultivation mode, can either systematically learn theoretical knowledge, or research the practical production problem in the oil field enterprise in time, and their research results can also be directly applied in the actual production process.

In order to adapt to the oil and gas well major, the reform of postgraduate education system, Petroleum Engineering College of Northeast Petroleum University, Daqing Oil field Institute, and Drilling Technological research Institute of Drilling Engineering Company construes the "oil and gas drilling engineering technology research center" together. To meet the classifiable training system of graduate students and achieve the school enterprise cooperation mode. Providing a platform that can take part in scientific research and solve the on-site practical engineering problems for students. Promoting school and enterprise level of scientific research and development ability comprehensively makes it become the research, development and promotion base of new products and technology.

\section{CONCLUSION}

Through culturing the education system reform and practice for many years and uniting the professional characteristics and cooperation with the oil field, the oil and gas engineering of the Northeast University of Petroleum has established a set of "science", "art" points system and the classified cultivation education mode ,and has achieved a good effect.

- In the cultivating mode of oil and gas engineering graduate, we closely linked to the practical of graduate training and integrated the actual content of oil engineering into the core curriculum system, then it has improved the students' ability to solve practical problems.

- Through the cooperation of oil and gas drilling R\&D center platform, oil enterprises and R\&D, we established a perfect training system of oil and gas engineering graduate and 
formed a set of graduate students system, classified training system which has the professional characteristics.

- The postgraduate classified cultivation mode promoted the professional graduates of oil and gas well engineering to enter the oil field to learn and practice early, and can combine the theory with the practical field organically to solve the practical problems in petroleum industry well.

\section{ACKNOWLEDGEMENTS}

This research was financially supported by Teaching reform project in Heilongjiang province department of education (JG2013010160), Graduate education teaching reform project in northeast petroleum university (JGXM_NEPU_201302), Teaching reform project in Heilongjiang province department of education (JG2014010636).

\section{REFERENCES}

[1] Shi Dinghuan . National innovation system : current status and future [M]. Beijing: Economic Management Press, 1999:5-28.

[2] Lu Lijun. Exploring the model of talent cultivation [D]. Hunan Normal University cooperative education, 2004.3.

[3] Zhao jingyuan, Sun Yuxue, Zhang Jihong, Li Shibin, Wang Jigang, Qu Guohui. Exploration and practice of university enterprise coperation to cultivate excellent engineers of petroleum engineering[J]. Petroleum Education, 2015.1. 